\title{
Triggering memories with online maps
}

\author{
S. Tejaswi Peesapati, Victoria Schwanda, Johnathon Schultz, Dan Cosley \\ Cornell University Information Science \\ 301 College Ave., Ithaca NY 14850 \\ \{stp53, vls48, jts228, drc44\}@cornell.edu
}

\begin{abstract}
The increasing popularity of applications that share location information over the internet enables the mapping of people's pictures and activities. Such applications often focus on the now, ignoring the importance of places and stories from the past. Inspired by recent work in HCI around reminiscing, in this paper we present a study in which 16 people used Google My Maps to write about their past, using place as a trigger for memories. People had a wide variety of strategies for choosing which places they remembered and the stories they told about those places; on balance they liked the idea of using maps as a tool for reminiscing, suggesting that this is a promising line of inquiry for further work.
\end{abstract}

\section{Keywords}

Online maps, reminiscence, memories, user interfaces.

\section{INTRODUCTION}

The physical nature of the world shapes us in fundamental ways. Aspects of our lives such as "home", "work", "school", "vacation", "friends", and "fun" are often tied to specific places. People attach meaning to place, both as groups (Harrison \& Dourish, 1996) and individuals (Rubinstein \& Parmelee, 1992). Thinking of these places can then be used to support reminiscence and identity building (Chaudhury, 2003), while our memories in turn influence the meanings we attach to a place (Rowles, 1983).

We believe that the intersection of technology, place, and reminiscing is a rich space to explore, both for better understanding the ways people remember the past and for developing systems that might improve people's lives. Research prototypes such as GeoNotes (Persson et al., 2003) and PlaceMail (Ludford et al., 2006), along with commercial products such as Google My Maps and foursquare, support the annotation of places and the recording of one's presence at a place. Cameras also often annotate pictures with location information. However, these tools, and social media more generally, are focused on the now (Peesapati et al., 2010). Their interfaces show the most recent picture, the newest location, and the latest blog entry, while earlier data is rarely reviewed.

This is unfortunate, because reminiscing has psychological benefits for both older adults (Webster \& McCall, 1999) and across the lifespan (Bryant et al., 2005). Recent HCI research explores people's practices around reminiscing, including how they use both digital and traditional media and artifacts to reminisce (Petrelli et al., 2008; Petrelli et al., 2009). That work in turn has informed the development of technologies that support both lifelogging - the capture and review of data about everyday life experience ( $\mathrm{Li}$ et al., 2010) from photos (Kalnikate et al., 2010) to spending data (Schwarz et al., 2009) — and reminiscing, both for families (Stevens et al., 2003; Petrelli et al., 2010) and individuals (Peesapati et al., 2010; Kalnikate et al., 2010).

In this paper we take a first step in exploring technologies that use place to support reminiscing. As a proof-ofconcept, we asked 16 people to use Google My Maps (Figure 1) to mark and describe places that were important to them, focusing on three main questions that might inform research and design around such systems:

- How did people choose places to tell stories about?

- What kinds of stories did they tell?

- Did they value the idea of reminiscing using My Maps?

For places and stories, we found variety: variety about what counted as important and worth marking and a wide range of styles for naming and describing places. Overall, however, there was agreement: on balance people enjoyed and valued using a map to write and think about their past.

\section{STUDY DESIGN}

The study was conducted online with remote participants using Google My Maps, which allows users to create

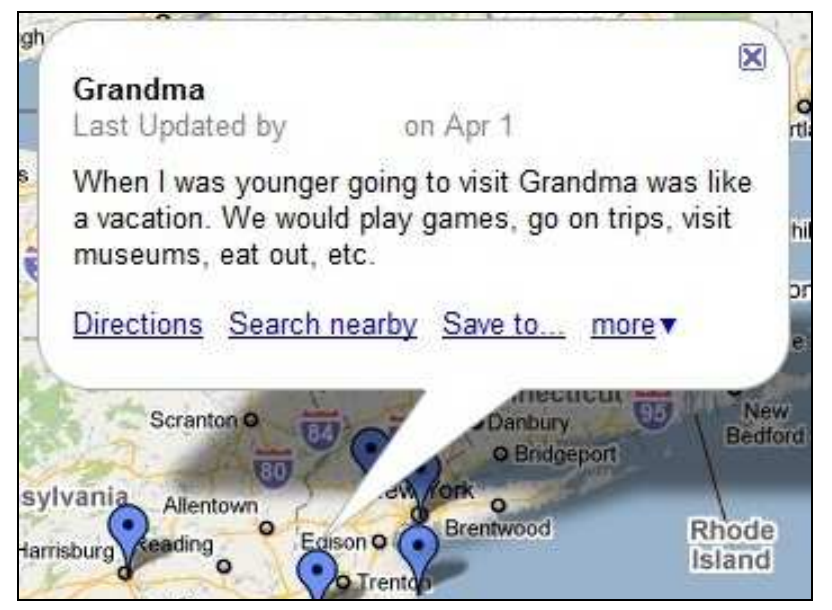

Figure 1. A placemark describing a childhood memory, taken from a participant's map. 
personal maps that contain "placemarks"-places people tag, then describe with text, photos, videos, or URLs. Figure 1 shows an example placemark from the study.

During each session, a researcher and the participant communicated using Google Chat, an IM client. Our pilot participants were unfamiliar with My Maps, so after obtaining consent, we asked people to view a five minute tutorial video about the interface. We then asked participants to mark locations that were important to them and to add a description of or story about the place if they wished. Participants were told they could stop at any time. While the experiment was in progress, the researcher was able to view the map, allowing us to observe participants' actions. After the participant finished, we followed up with a short interview about their reasons for marking certain locations, the order they followed, and their overall experience.

We interviewed a total of 16 participants (12 female, 4 male). All were undergraduates solicited through an experiment recruiting website at a large U.S. university, and they received course credit for participating. They spent about 17 minutes and marked about 10 locations on average.

\section{RESULTS AND DISCUSSION}

In this section we discuss people's use of and reactions to reminiscing with My Maps, focusing on three themes. The first is how people made their maps: what places did they choose to mark, and which did they choose to avoid? The second is how people described these places: what did they talk about, and how much did they say? And the third is how people felt about My Maps: what did they think it might be good for? Was it fun or useful for reminiscing, and would they use it, or similar tools, in the future?

\section{Marking Places}

Participants marked between 3 and 32 placemarks, with an average of 10 . Figure 2 shows that most participants marked close to the average number of placemarks with only a few participants marking many more or fewer placemarks than average. Corresponding descriptions ranged in length from 0 to 167 words, with an average of 24. Although the length varied widely between participants, individuals tended to write descriptions of about the same length. There was a weak negative correlation between the number of placemarks a person tagged and the average length of descriptions $(\mathrm{r}=-0.34)$.

Places have a number of associations. Participants used a number of strategies for deciding what to mark. Place names often served as memory triggers, as participants were reminded about their attachment with a place by seeing the name of the place on the map.

"If I saw a name of a city it may have triggered a memory and that's when I marked it."

Some participants followed chronological ordering, starting with places from their childhood and moving toward the

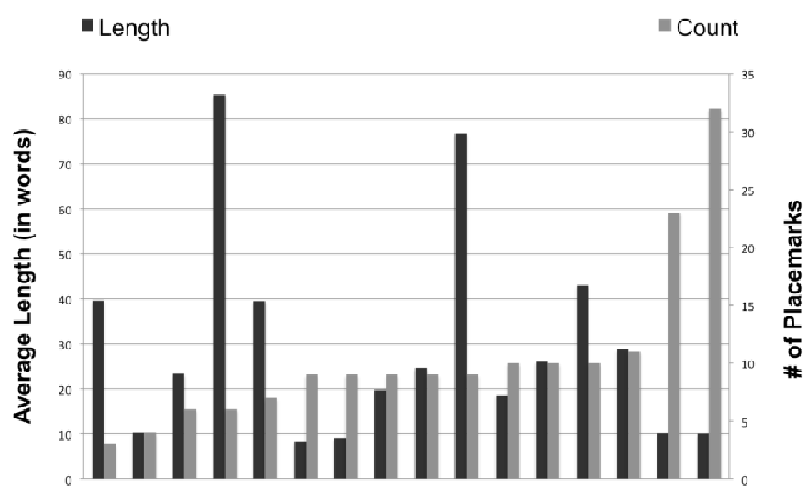

Figure 2. Number of placemarks tagged and average placemark description length for each participant, ordered by number of placemarks added.

present day. Others followed chains of reminiscence, as the act of marking a place may have triggered another memory which was then marked; as one participant said, "Certain memories triggered other memories." A few had trouble getting started thinking of places at all, while others used a variety of strategies and reminders:

\section{"It mostly went by theme: daily places, ballet, summer places, friends (homes and hang-out places), places away from New York."}

Many participants started their virtual journey into the past by marking "home" as their first placemark. This home often referred to their childhood home or that of their parents or grandparents to which they felt emotionally attached. A few participants marked their current home.

Not all places are worth remembering. People avoided marking some places, such as those with bad memories. When people did mark such places, they described them as funny and adventurous when they look back today, in keeping with Webster \& McCall (1999)'s finding that reminiscing helps people work through the past.

"[I marked it] because it was a funny experience. It was pretty bad and low at the time being, but then it got stuck to my memory which I can laugh at with my friends later."

Many people also avoided marking places related to routines that they consider boring:

"I was thinking about marking my home town too but it was kind of a boring stuff so I decided not to. It's like school-after school-after school private tutoringhomework-repeat."

However, not all routines are boring:

"[I tagged] whatever came to mind in regards to my daily routine...like places I run."

\section{Describing Places}

People's descriptions of places were also quite varied. We developed a codebook consisting of hierarchical categories 


\begin{tabular}{|c|c|c|}
\hline Category & \# of Descriptions & Percentage \\
\hline Places & $\mathbf{9 7}$ & $\mathbf{5 8 \%}$ \\
\hline School/Work & 26 & $27 \%$ \\
\hline Vacations & 25 & $26 \%$ \\
\hline Home & 18 & $19 \%$ \\
\hline Other Places & 16 & $16 \%$ \\
\hline Outdoors & 12 & $12 \%$ \\
\hline Things & $\mathbf{4 0}$ & $\mathbf{2 4 \%}$ \\
\hline Activities & 26 & $65 \%$ \\
\hline Events & 8 & $20 \%$ \\
\hline Food & 6 & $15 \%$ \\
\hline People & $\mathbf{3 0}$ & $\mathbf{1 8 \%}$ \\
\hline Family & 19 & $63 \%$ \\
\hline Friends & 9 & $30 \%$ \\
\hline Loved Ones & 2 & $6 \%$ \\
\hline
\end{tabular}

Table 1. Placemark descriptions by category. The table displays hierarchical nesting of categories.

of "things" (like swimming, concerts and cheesecake), "people" (like father, John, boyfriend) and "places" (like playground, garage, home) with one level of subcategories. Though descriptions often had aspects of multiple categories, each was assigned to only one primary category. Two people independently coded the descriptions, and disagreements were settled by one of the researchers. ${ }^{1}$

Places, things, and people all mattered. Table 1 shows that, as might be expected given the use of place as a memory trigger, "place" was often the dominant theme. "Things" and "people" were reminisced about less often (24\% and $18 \%$ of placemarks respectively). Figure 3 shows that participants varied widely in whether they focused on places associated with things, people, or some of both. As Table 1 shows, most "things" were important activities in people's lives: places one participant ran, or where another practiced and performed ballet. "People" were family and friends, who had close relationships and shared experiences with participants:

"Actually it was usually a trip that first came to mind. Then some people followed usually my family."

People tell different kinds of stories. Figure 2 showed that people varied widely in the length of their descriptions. People also varied in the ways they described their placemarks. Personal stories, as in Figure 1, were common, as were short descriptions of the function of the place. People also varied on how they named their placemarks. Some people used a proper place name, like "New York, NY"; others described the type of place, like "library"; a

${ }^{1}$ Intercoder agreement ranged from $85-91 \%$ (mean $88 \%$ ) for parent and $80-91 \%$ (mean $86 \%$ ) for child categories. Krippendorf's Alpha ranged from 0.68-0.71 (mean 0.70) for parent and 0.63-0.73 (mean 0.69) for child categories.

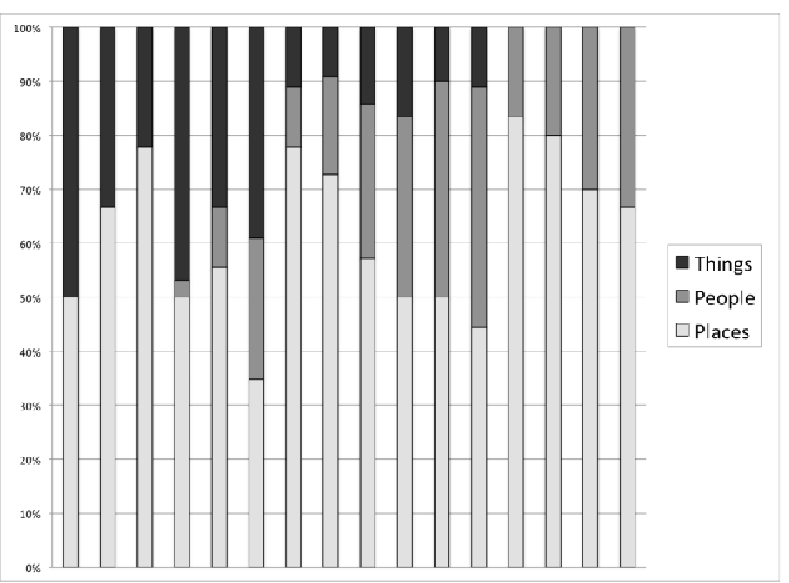

Figure 3. Percentage of individual participants' descriptions categorized as things, people, and places, sorted by balance between things and people.

third group used names that emphasized their personal relationship to the place, like "relatives' home".

This variety suggests that probably there isn't a single system for helping people to reminisce with place, but that many different systems or interfaces may be needed to effectively facilitate reminiscing. We also speculate that being able to see examples of other people's maps might influence the way people name and describe placemarks.

\section{Reactions to reminiscing with places}

People had a number of reactions to the idea of reminiscing using maps.

People saw a variety of potential uses. Our initial vision was to help people reminisce, but people saw a variety of potential uses for these maps, including trip and vacation planning and daily activity logging, not unlike a diary or journal. People also suggested social uses, sharing with friends and family for trip advising and group reminiscing. This suggests that designs should allow people sufficient flexibility to appropriate the application for their own needs, and that providing social features like sharing may improve both mapping tools and tools for reminiscing.

Media elements enrich the experience. We asked people to add text descriptions, but some would have liked to add additional media elements like photos and videos to their descriptions of placemarks. One participant used the "Street View" feature of Google Maps to virtually revisit places, creating a sense of nostalgia:

"When I used street view to look for the specific locations that I marked, I was reminded of how I felt when I was actually there."

This suggests that making it easy for people to add personal content to placemark descriptions may better support their storytelling needs.

Many people liked the idea of reminiscing using maps. Overall, people's reactions were positive. People described 
the system as a diary and a tool for connecting to other people, and though a few people didn't see a use for a system like this, people were on balance positive:

\section{"It was fun to take the time to reminisce. And I enjoyed charting my memories on a map-it almost made the memories more concrete, and I was more easily able to remember them. It was also a neat way to chart my travels."}

Several people suggested that they might go back and add more places to their map. However, eight weeks after the experiment concluded, no one had marked a new place, suggesting that reminders may be needed to encourage continued use of these kinds of lifelogging applications.

\section{CONCLUSION AND FUTURE WORK}

This study suggests that place may be valuable for reminiscing, but raises a number of further questions. It would be useful to compare place to other kinds of triggers and media for supporting reminiscing. Maps focused on reminiscing may also be different from maps created for other uses such as recording individual trips and lists of favorite places, and those differences might give us insight into reminiscing behavior. Our findings also suggest specific design choices to explore. People wanted to add their own pictures and videos to the map, so priming them to reminisce by using geo-tagged content they already create in other systems might be useful. Likewise, as in Peesapati et al. (2010), people wanted to have social, shared elements in their maps and reminiscing.

We also would like to explore how changing the conditions of mapping affects people's behavior. We wonder if showing people long, evocative example descriptions might encourage them to also tell more detailed stories about their past. The idea of embodiment (Dourish, 2001) suggests that using a mobile phone and reminiscing in the physical world may be more engaging than reminiscing using a My Mapslike interface. Finally, we would like to see how explicit reminders would affect people's use of a system like this, and of reminiscing and lifelogging tools more generally.

These questions, and people's reactions, suggest there is real value in joining technology, place, and reminiscence. People's experiences are rarely recorded and eventually lost to them, to their families, and to future generations looking to understand them. Supporting this kind of memory is an understudied question in information science, and we hope this work helps to take a step in this direction.

\section{ACKNOWLEDGMENTS}

We thank Meethu Malu for her tireless interviewing work, and NSF for support through grant number IIS 0845351.

\section{REFERENCES}

Bryant, F., Smart, C., King, S. (2005). Using the past to enhance the present: Boosting happiness through positive reminiscence. J. Happiness Studies, 6:227-260.
Chaudhury, H. (2002). Place-biosketch as a tool in caring for residents with dementia. Alzheimer's Care Quarterly, 3(1), 42-45.

Dourish P (2001) Where the action is: the foundations of embodied interaction. MIT Press, Cambridge, MA

Harrison, S. \& Dourish, P. (1996). Re-place-ing space: the roles of place and space in collaborative systems. In Proc. CSCW 1996, 67-76.

Kalnikaite, V., Sellen, A., Whittaker, S., \& Kirk, D. (2010). Now let me see where I was: understanding how lifelogs mediate memory. In Proc. CHI 2010, 2045-2054.

Li, I., Dey, A., \& Forlizzi, J. (2010). A stage-based model of personal informatics systems. In Proc. CHI 2010, 557566.

Ludford, P.J., Frankowski, D., Reily, K., Wilms, K., \& Terveen, L. (2006). Because I carry my cell phone anyway: functional location-based reminder applications. In Proc. CHI 2006, 889-898.

Peesapati, S.T., Schwanda, V., Schultz, J., Lepage, M., Jeong, S., \& Cosley, D. (2010). Pensieve: supporting everyday reminiscence. In Proc. CHI 2010, 2027-2036.

Persson, P., Espinoza, F., Fagerberg, P., Sandin, A., \& Cöster, R. (2003). GeoNotes: a location-based information system for public spaces. In Designing Information Spaces: the Social Navigation Approach, K. Höök et al., Eds. Springer-Verlag, London, 151-173.

Petrelli, D. Hoven, E., \& Whittaker, S. (2009). Making History: Intentional Capture of Future Memories. In Proc. CHI 2009, 1723-1732.

Petrelli, D., Villar, N., Kalnikaite, V., Dib, L., \& Whittaker, S. (2010). FM radio: family interplay with sonic mementos. In Proc. CHI 2010, 2371-2380.

Petrelli, D., Whittaker, S., \& Brockmeier, J. (2008). Autotopography: what can physical mementos tell us about digital memories? In Proc. CHI 2008, 53-62.

Rowles, G.D. (1983). Place and personal identity in old age: Observations from Appalachia. Journal of Environmental Psychology, 3(4), 299-313.

Rubinstein, R. L. \& Parmelee, P.A. (1992).Attachment to Place and the Representation of the Life Course by the Elderly. In Place Attachment, I. Altman \& S.M. Low, Eds. Plenum, New York.

Schwarz, J., Mankoff, J., \& Matthews, H.S. (2009). Reflections of everyday activities in spending data. In Proc. CHI 2009, 1737-1740.

Stevens, M.M., Abowd, G.D., Truong, K.N., \& Vollmer, F. (2003). Getting into the Living Memory Box: Family archives \& holistic design. Pers. Ubiquitous Computing, 7(3-4):210-216.

Webster, J.D. \& McCall, M.E. (1999). Reminiscence functions across adulthood: A replication and extension. J. Adult Dev., 6(1):73-85. 